\title{
Asymptomatic Leishmania infantum infections in humans living in endemic and non-endemic areas of Croatia, 2007 to 2009
}

K Šiško-Kraljević (katarina.sisko.kraljevic@mefst.hr) ${ }^{1,2,3}$, A Jerončićc ${ }^{3,4}$, B Mohar ${ }^{1}$, V Punda-Polić ${ }^{1,5}$

1. Department of Medical Microbiology, Split University School of Medicine, Split, Croatia

2. Department of Microbiology, Public Health Institute of Split and Dalmatia County, Split, Croatia

3. These authors contributed equally to this work and share first authorship

4. Department for Research in Biomedicine and Health, Split University School of Medicine, Split, Croatia

5. Department of Clinical Microbiology, Split University Hospital, Split, Croatia

Šiško-Kraljević K, Jerončić A, Mohar B, Punda-Polić V. Asymptomatic Leishmania infantum infections in humans living in endemic and non-endemic areas of Croatia, 2007 to 2009. Euro Surveill. 2013;18(29):pii=20533. Available online: http://www.eurosurveillance.org/ViewArticle.aspx?Articleld=20533

Article submitted on 23 August 2012 / published on 18 July 2013

The prevalence of asymptomatic leishmaniasis in the general population of Croatia has not been studied to date. To assess the prevalence of Leishmania infantum specific IgG antibodies among immunocompetent residents of Croatia, sera from 2,035 persons (eastern coast of Adriatic Sea, $n=1,186$; Adriatic islands, $n=653$; mainland, $n=196$ ), were tested by an enzyme immunoassay. A total of 231 (11.4\%) persons had anti-Leishmania antibodies. Multivariate analysis revealed that seropositivity was associated with geographic location and age. Residents of coastal areas and islands were significantly more seropositive than mainland residents (odds ratios (OR) 20.37 to 28.51). Moderate to high anti-Leishmania seroprevalence was found throughout the eastern Adriatic coast and islands (4.0\% to $22.2 \%$ ) including the sites previously considered non-endemic. A highly endemic focus was identified in central coastal Dalmatia (seroprevalence 22.2\%; OR: 1.72; 95\% confidence interval (CI): 1.332.22). Regarding age, children aged $0-9$ years were the most vulnerable group for asymptomatic Leishmania infection (OR: 2.19; $95 \% \mathrm{Cl}$ : 1.16-4.14).

\section{Introduction}

Leishmaniasis is caused by Leishmania spp., hemoflagellate protozoa belonging to the family Trypanosomatidae. Infected phlebotomine sandflies serve as vectors for the transmission of all Leishmania species. Human leishmaniasis can be divided into three main disease manifestations: (i) visceral leishmaniasis (VL), (ii) cutaneous leishmaniasis (CL) and (iii) mucocutaneous leishmaniasis (ML). The strain of the infecting organism and the host's immunologic status greatly influence clinical manifestations.

Zoonotic VL caused by Leishmania infantum is endemic in Mediterranean countries of Europe and domestic dog is the main reservoir [1-3]. During the last decade, there have been reports of spreading leishmaniasis northward into previously non-endemic areas of central and northern Europe [1-3]. It is well known that, besides clinical cases of VL, asymptomatic infections are common in endemic areas $[2,3]$.

Croatia encompasses $56,538 \mathrm{~km} 2$. According to the 2011 census, it had a population of $4,284,889$ [4]. Geographically, Croatia is composed of three areas: the Adriatic coastal zone with islands in the south, the Pannonian Plain in the north, and the mountainous region in-between. The Croatian littoral comprises a relatively narrow land belt with islands along the eastern coast of the Adriatic Sea (Figure). The littoral is traditionally divided into two large areas based on geography, ecology and cultural heritage: the northern (Istria and Primorje counties) and the southern part (Dalmatia) which is further subdivided into northern, central and southern Dalmatia. The Adriatic islands and the coastal zone are characterised by Mediterranean climate which provides good living conditions for sandfly vectors of Leishmania [5,6]. Continental Croatia has temperate continental or continental climate and is usually considered free of phlebotomine vectors of Leishmania.

Human VL and canine VL has been reported in central and southern coastal and insular Dalmatia (from Split to Dubrovnik) since 1930 [7]. From 1931 to 1957, 398 human VL cases were diagnosed in this region [8]. A case of CL was firstly recorded in 1945 and $201 \mathrm{CL}$ cases were recorded by 1957 . After the late 1950 s, the number of VL cases declined, probably because of mass spraying with antimalarial insecticides [8]. Since 1990, studies have identified re-emerging foci of both human and canine VL in central and southern Dalmatia [9-11].

In Croatia notification is compulsory for both VL and $\mathrm{CL}$, although these diseases are not included in the decisions of the European Parliament for reporting communicable diseases $[12,13]$. Medical practitioners are notifying human leishmaniasis cases through 
Croatia's health information system or directly to the epidemiologist in the regional public health institutes. Cases are defined as probable which is a case clinically compatible in endemic region or with epidemiological connection to a confirmed case, and confirmed that is a case laboratory-confirmed by positive parasitological (microscopy or cultivation) and serological (IFA, ELISA) tests. Case definitions for $C L$ are similar, excluding the serological tests [13]. According to data periodically published by the Croatian National Institute for Public Health there were between one and four new cases of VL reported each year in Croatia in the last decade [14]. The estimated mean annual incidence of human leishmaniasis is 0.4 per 100,000 population [5]. Leishmaniasis in Croatia is described as predominately paediatric disease: almost half of VL patients are children up to the age of 10 years and the disease is more often found in men $[9,10]$. Most of the reported cases occurred among inhabitants of the Croatian coast and islands $[9,10]$. Besides this, few VL cases were diagnosed in Austrian [15] and Hungarian [16] tourists after returning from the Dalmatian littoral.

Recently, three Phlebotomus species, known to serve as vectors for $L$. infantum were found in central and southern coastal and insular Dalmatia [5]. A veterinary seroepidemiologic survey conducted in central Dalmatia among apparently healthy dogs using dotELISA, found canine seroprevalence ranging from zero to $42.85 \%$, which was in accordance with previous recognition of central and southern coastal and insular Dalmatia as a high endemic foci of $L$. infantum for dogs [11]. In contrast to high seroprevalence ratios in dogs, no information about the prevalence of the infection in otherwise healthy human inhabitants of different Croatian regions is available.
The aim of this study was to assess the prevalence of IgG antibodies to $L$. infantum among healthy people living in different regions of Croatia, and to compare the seroprevalence in endemic regions with that in non-endemic regions. This is the first investigation on asymptomatic leishmaniasis in residents of Croatia.

\section{Methods}

The target population for our study was the apparently healthy general population in previously recognised endemic and non-endemic areas for leishmaniasis in Croatia. The studied areas known as endemic areas: insular Croatia, and central and southern Dalmatia, as well as areas previously considered nonendemic but with favourable Medieranean climate: northern Dalmatia, Istria and Primorje. Two counties in northern Croatia with continental climate where sandflies were considered rare or absent: Brod-Posavina County (centre Slavonski Brod) and the most north-western Međimurje County (centre Čakovec), were also included.

\section{Serological survey}

Serum samples were collected from 2007 to 2009 to examine the prevalence of IgG antibodies to $L$. infantum in Croatia. We used 'residual' sera of apparently healthy, immunocompetent individuals who did not show any symptoms of leishmaniasis and came to hospitals or clinics for routine laboratory check-ups or for blood donation. Participating hospitals' or clinics' laboratories were selected according to their geographic location: 14 served population along the Adriatic coast and two were from non-endemic parts of Croatia. Laboratories provided data on age, sex and site of residence for the study participants.

\section{TABLE 1}

Sex distribution in the study population $(n=2,035)$ compared with that of the total Croatian population

\begin{tabular}{|c|c|c|c|c|c|c|c|c|}
\hline & $\begin{array}{l}\text { Individuals } \\
\text { tested }\end{array}$ & Male & $\begin{array}{l}\text { Percentage } \\
\text { (\%) }\end{array}$ & \multicolumn{2}{|c|}{$(95 \% \mathrm{Cl})$} & $\begin{array}{c}\text { Census } \\
\text { population }\end{array}$ & Male & $\begin{array}{c}\text { Percentage } \\
(\%)\end{array}$ \\
\hline \multicolumn{9}{|l|}{ All } \\
\hline Adriatic coast & 1,186 & 571 & 48.15 & $45.30 \%$ & $50.99 \%$ & $1,247,133$ & 605,605 & 48.56 \\
\hline Adriatic islands & 653 & 268 & 41.04 & $37.27 \%$ & $44.81 \%$ & 113,875 & 56,658 & 49.75 \\
\hline Croatian mainland $^{\mathrm{a}}$ & 196 & 137 & 69.90 & $63.48 \%$ & $76.32 \%$ & $2,923,881$ & $1,404,072$ & 48.02 \\
\hline \multicolumn{9}{|l|}{ Region/Site of residence } \\
\hline \multicolumn{9}{|l|}{ Adriatic coast } \\
\hline Istria and Primorje & 117 & 47 & 40.20 & $(31.32 \%$ & $49.08 \%)$ & 467,678 & 226,115 & 48.35 \\
\hline Nothern Dalmatia & 159 & 84 & 52.80 & $(45.04 \%$ & $60.56 \%)$ & 255,158 & 124,849 & 48.93 \\
\hline Central Dalmatia & 571 & 293 & 51.30 & $(47.20 \%$ & $55.40 \%)$ & 419,131 & 203,513 & 48.56 \\
\hline Southern Dalmatia & 339 & 147 & 43.40 & $(38.12 \%$ & $48.68 \%)$ & 105,166 & 51,128 & 48.62 \\
\hline \multicolumn{9}{|l|}{ Croatian mainland } \\
\hline Brod-Posavina county ${ }^{a}$ & 107 & 96 & 89.70 & $(84.0 \%$ & $95.5 \%)$ & 158,575 & 77,115 & 48.60 \\
\hline Međimurje county & 89 & 41 & 46.10 & $(35.7 \%$ & $56.4 \%)$ & 113,804 & 55,601 & 48.90 \\
\hline
\end{tabular}

$\mathrm{Cl}$ : confidence interval.

a Healthy donor effect bias present in Brod-Posavina county as blood donors constituted the majority of the sample. 
To determine the target sample size for each region we used published statistical tables, which provide minimal sample sizes that are necessary for given combinations of precision, confidence levels, and variability.

A minimum of 1,100 individuals were selected as the target sample size for the coastal region with previously recognised endemic foci in order to reach the precision level of $\pm 3 \%$ under assumption of the confidence level of $95 \%, p=0.5$ and the size of population greater than 100,000 inhabitants. For islands, the targeted precision on population with more than 100,000 inhabitants was $\pm 5 \%$ resulting in a minimum sample size of 400 , whereas for the reference non-endemic continental region, under the assumption of maximum seroprevalence of $2 \%$, the targeted sample size was 84 to reach the $\pm 3 \%$ precision level.

Convenience sampling was used to select respondents in the most economically, technically, and operationally feasible method [17].

To estimate whether the study sample represents the research setting population, we compared the percentage of men estimated from the study sample with the 2011 census data (Table 1).

We classified sites based on their seroprevalence as 'high endemic focus' and 'moderate seroprevalence'. We derived these definitions combining the data from the literature with the results of this study. In particular, in a study by Federico et al. a seroprevalence of $L$. infantum infection of $4 \%$ in the Rome and Caltanissetta area was marked as 'moderate' [18] whereas Marty et al. detected a seroprevalence of $38 \%$ in the high endemic focus of Alpes-Maritimes, using Western blot technique, which is more sensitive than the technique used in this study [19]. The seroprevalence rate in the majority of our coastal areas was around $7 \%$ and defined as 'moderate seroprevalence'. The one area with a seroprevalence of $22 \%$ had a significantly higher seroprevalence in comparison with surrounding areas, all of which were classified as 'moderate seroprevalence'. Therefore, that site was defined as a 'high endemic focus' and the definition was further supported by epidemiological data since the majority of cases of VL in Croatia are reported from 'high endemic foci' [5,9-11].

Sera were tested for the presence of IgG antibodies to L. infantum by commercial enzyme-linked immunosorbent assay (NovaLisa Leishmania infantum IgG, NovaTec Immunodiagnostica GmbH, Dietzenbach, Germany), according the manufacturer's instructions. Declared specificity and sensitivity of the test were $85 \%$ and $91 \%$ respectively. A serum was considered positive when the ratio between the optical density (OD450) value of the serum and the cut-off was $>1.1$.

The study was approved by the ethics committees of the Split University School of Medicine and of the Split
University Hospital. Individual informed consent was not required according to the ethical committee.

\section{Statistical analyses}

Data were analysed with statistical package SPSS 19.0 (SPSS; Chicago, Illinois, US). Associations of seropositivity with sex or geographic region were tested by Pearson's chi-square test whereas the significance of difference in median age of participants by seropositivity was tested by Mann-Whitney $U$ test. The strength of association between seropositivity and the site of residence was estimated by odds ratio (OR), 95\% Cl and $\mathrm{p}$-values. For each site observed seroprevalence was compared to unweighted average rate in the accompanying region (i.e. coastal or continental) and ORs were calculated from the standard $2 \times 2$ table.

A multiple logistic regression analysis was used to evaluate the potential risk factors associated with Leishmania infection, including age as categorical variable, sex, and region of residence. Significance level was set at 0.05 . In case of multiple testing, we adjusted the $p$-values with the Bonferroni correction.

\section{Results}

Blood specimens from 2,035 persons (975 men and 1,060 women) were collected. These included 1,186 persons in the coastal area from Istria to the Montenegro border, 653 on Adriatic islands and, for comparison, 196 residents of two northern continental Croatian counties (Table 2). The survey enrolled persons from all age groups, ranging from eight months to 88 years, with the median of 42 years (interquartile range (IQR): 21-59). The large deviation from the census data was observed only in the reference site in Brod-Posavina County, in which blood donors were overrepresented.

Of the total of 2,035 sera of healthy residents, antiL. infantum IgG antibodies were found in 231 (11.4\%). Seroprevalence differed significantly among Croatian sites ranging from $0.0 \%$ in Brod-Posavina County to $22.2 \%$ in central Dalmatia $(x 2=112.24 ; d f=13 ; P<0.001)$ (Figure, Table 1). Overall, according to the place of residence, we found a strong association between seropositivity and residence in island, coast, or continental areas $(x 2=35.41 ; d f=2 ; P<0.001)$. Post hoc chi-square analysis revealed that inhabitants of coastal areas had significantly higher seroprevalence than islanders $\left(x_{2}=9.27 ; d f=1 ;\right.$ Pcorr $\left.=0.007\right)$ or those from the two continental regions $(x 2=29.43 ; d f=1$; Pcorr<0.001). Furthermore, islanders had significantly higher seroprevalence than continental inhabitants ( $x 2=17.37$; $d f=1$; Pcorr<0.001).

To analyse the spatial distribution pattern of Leishmania infection in more detail, we estimated strength of associations of seropositivity with the site of residence in particular regions: coastal, continental, or islands (Table 3). Only in Adriatic coastal counties seroprevalence of sites differed significantly from the average regional rate. While central Dalmatia inhabitants had 


\section{FIGURE}

Geographic distribution of seroprevalence for anti-Leishmania IgG in asymptomatic healthy individuals, Croatia, 2007$2009(n=2,035)$

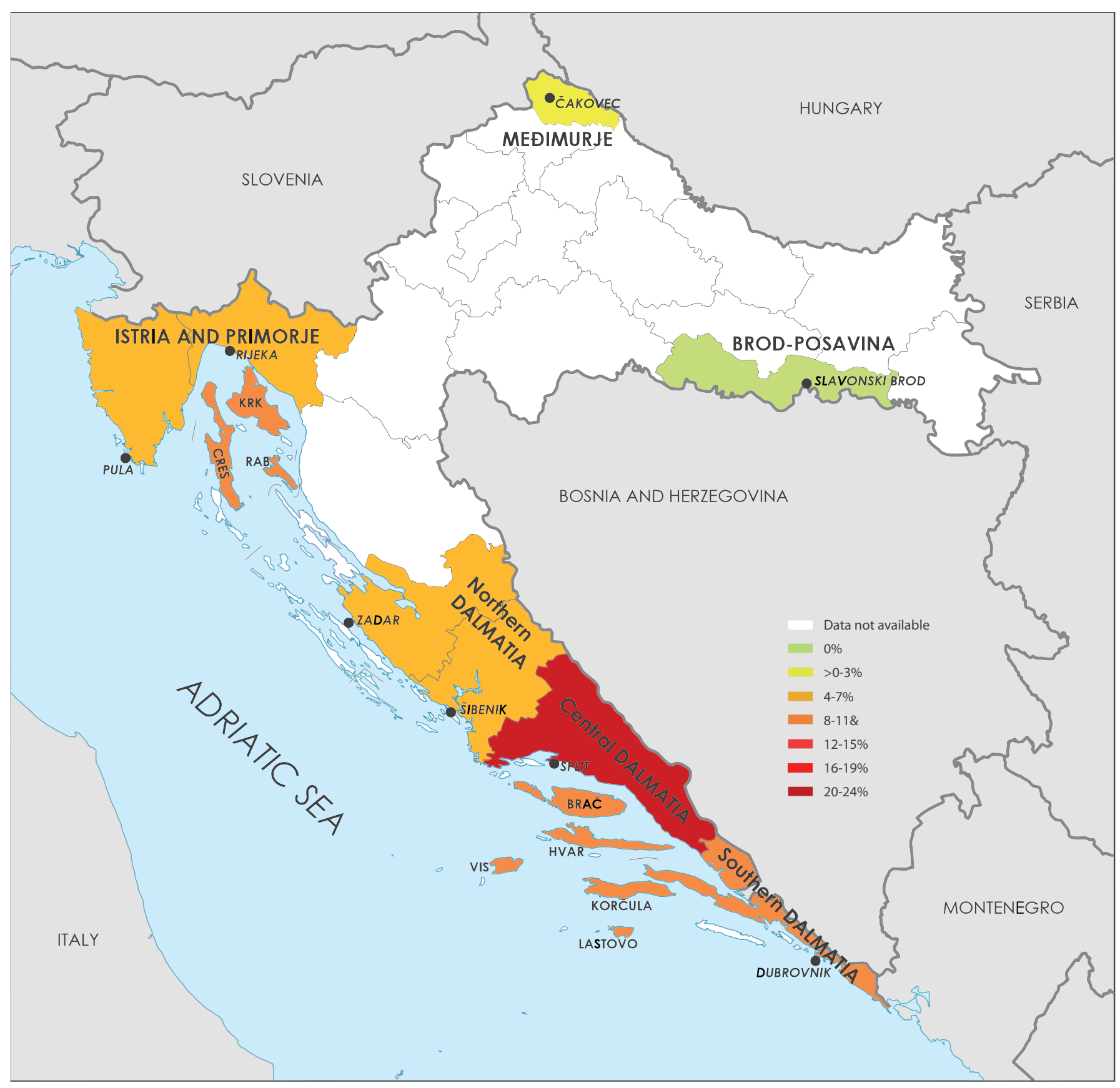


the highest prevalence of antibodies and the highest risk for Leishmania infection (OR: $1.72 ; 95 \% \mathrm{Cl}: 1.33$ to 2.22; p 0.001 ), residents of the rest of coastal areas had lower risk (OR: 0.27 to 0.52 ; $p$-value: 0.002 to 0.006) as compared to the average rate in the coastal region. Although these results clearly indicated central Dalmatia as a high endemic focus for Leishmania infection, the observed seroprevalence in other coastal areas (ranging from $4.3 \%$ to $8.0 \%$ ) also indicated these areas as endemic sites where the seroprevalence was higher than in continental Croatia.

Regarding sex and age as potential risk factors, we found no association of seroprevalence with sex $(x 2=0.11 ; d f=1 ; p=0.739)$. Among 975 men, antibodies were found in 113 (11.6\%) sera, while among 1,060 women, antibodies were found in $118(11.1 \%)$ sera. This finding was further confirmed by the multivariate model with seropositivity as dependent, and age, sex and geographic location as independent variables. Multivariate logistic regression analysis of Leishmania seropositivity in association with age, sex and geographic location is shown in Table 4.

In contrast to sex, we found significant differences in the median age of seropositive and seronegative persons: 40 years (IQR: $16-58$ ), and 42 years (IQR: 22-60), respectively (Mann-Whitney $U$ test, $p=0.039$ ). This indicated age as a risk factor for Leishmania infection. Additionally, in the multivariate model with age, sex and geographical region as covariates, age was a significant predictor of seropositivity (overall significance $p=0.022$ ). The rates of seroprevalence for each age group of participants as well as the associated $O R$ with $95 \% \mathrm{Cl}$ adjusted for covariates are shown in Table 4. Results show that Leishmania seropositives are most likely in o to 9 year-olds (17.5\%; OR: 2.19 ; $95 \%$ $\mathrm{Cl}: 1.16-4.14)$. It is noted that anti-Leishmania antibodies were found in nine of a subgroup of 71 children under the age of four, including one girl aged one year old. The data also show that Leishmania seropositivity does not continuously change with age. Instead, a bimodal distribution is indicated with comparable high risk of asymptomatic infection in those aged o to 9,10 to 19 and 40 to 49 years (OR: 1.84 to 2.19 ; all $p$-values $(0.05)$. In contrast, people of all other age groups had similar risk for Leishmania infection to those in the 30 to 39-year-old reference age group (OR: 1.00 to 1.33; p-values: 0.374 to 0.992 ).

\section{Discussion}

To our knowledge, this is the first study of the prevalence of asymptomatic Leishmania infection in the general population of Croatia. In order to determine the Leishmania infection distribution, residents of various geographical and ecological areas were included in a serological survey. The findings of this study reveal a strong association of seropositivity with geographic region (east Adriatic coastal and islands areas) and age group. The presence of seropositive people in northwestern coastal and island regions (Istria and

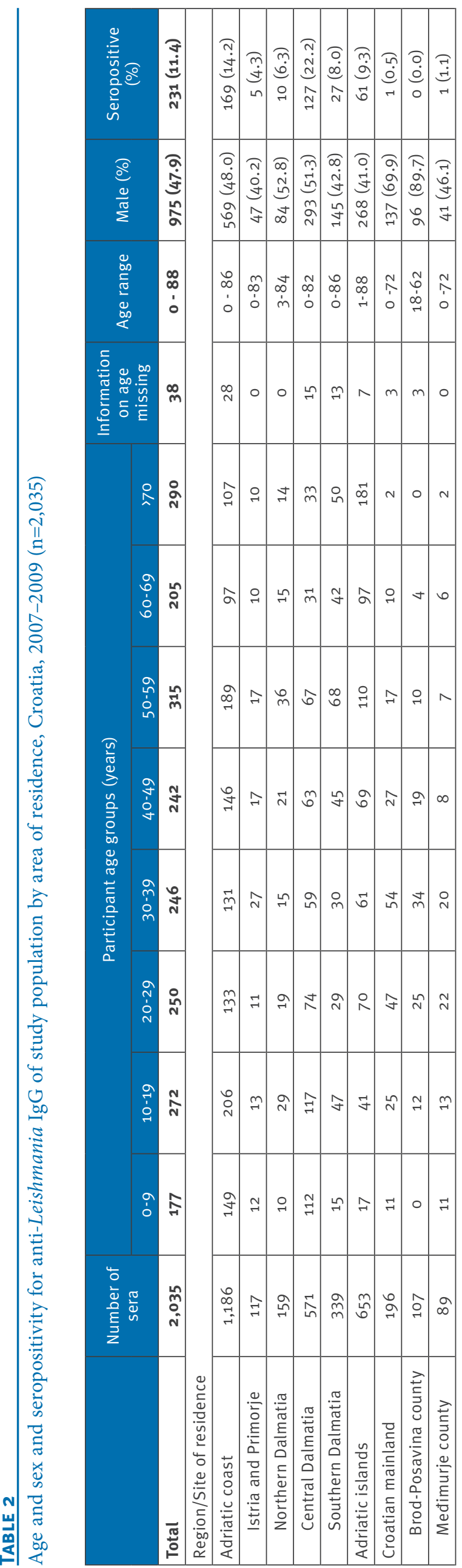


Seroprevalence of anti-Leishmania IgG by residence compared with unweighted average in the associated region, Croatia, 2007-2009, $(n=2,035)$

\begin{tabular}{|c|c|c|c|}
\hline & $p$-value & OR & $95 \% \mathrm{Cl}$ \\
\hline \multicolumn{4}{|l|}{ Region/Site of residence } \\
\hline Adriatic coast & \multicolumn{3}{|c|}{ Reference: seropositivity $14 \%$ ( $95 \% \mathrm{Cl}, 12-16 \%)$} \\
\hline Istria and Primorje & $0.002^{\mathrm{a}}$ & 0.27 & $0.11-0.67$ \\
\hline Northern Dalmatia & $0.006^{a}$ & 0.4 & $0.21-0.78$ \\
\hline Central Dalmatia & $<0.001^{\mathrm{a}}$ & 1.72 & $1.33-2.22$ \\
\hline Southern Dalmatia & $0.002^{\mathrm{a}}$ & 0.52 & $0.34-0.80$ \\
\hline Adriatic islands & \multicolumn{3}{|c|}{${ }^{b}$ seropositivity $9 \%(8-11 \%)$} \\
\hline Croatian mainland & \multicolumn{3}{|c|}{ Reference: seropositivity $0.2 \%(0.1-0.9 \%)$} \\
\hline Brod-Posavina county & 0.758 & 0 & NA \\
\hline Međimurje county & 0.849 & 2.22 & $0.14-35.83$ \\
\hline
\end{tabular}

$\mathrm{Cl}$ : confidence interval; NA: not applicable; OR: odds ratio.

a Significant at level 0.01 .

b Site samples were too small for reliable comparison.

Primorje) where cases of VL have not been reported yet, suggests that Leishmania transmission toward north may have occurred.

A highly endemic focus in central Dalmatia was confirmed in accordance with previous reports of both canine and human leishmaniasis in central and southern Dalmatia's coast and islands [5, 7-11]. However, the northwestern part of the Adriatic littoral, including Istria, Primorje, and northern Dalmatia, was considered a non-endemic region [5, 7-11]. In 2002, a case of VL was diagnosed in a patient who had no history of travel to known endemic regions and apparently had contracted the infection during his stay on the Velebit Mountain in northern Dalmatia [20]. Our results confirm this observation as they indicate that asymptomatic Leishmania infection is found throughout the eastern Adriatic coast and islands. Depending on the geographical location, a moderate to high ( $4 \%$ $22 \%)$ prevalence of asymptomatic infection has been observed.

Data from seroepidemiological studies conducted in other Mediterranean countries have also shown a variable prevalence (from 0.5 to $56 \%$ ) of Leishmania infections depending on the geographic regions studied and on the test used for detection [3,21]. In our study we used a commercial ELISA as a relatively simple method for testing a large number of sera. Convenience sampling was used for selecting respondents. Despite some of its limitations, in a study by Kelly et al. it was shown that a convenience sample of sera from diagnostic laboratories was an appropriate sampling strategy to provide population immunity data to inform country's health policies [17]. Although the healthy donor effect bias was present in Brod-Posavina County, blood donors represented only a minority in other sites and are not expected to have influenced results.

The highest prevalence of $\mathbf{2 2 . 2} \%$, significantly higher than in other coastal zones, was found in central Dalmatia. In comparison with other coastal areas, central Dalmatia has a high background of canine leishmaniasis and sandflies $[5,6,11]$ which are likely to be associated with high prevalence of asymptomatic Leishmania infection among residents in this area. Central Dalmatia is also an active focus with the highest number of human VL cases in Croatia $[9,10,14]$. Most of VL cases diagnosed in Croatia during the study period from 2007 to 2009 occurred in central Dalmatia: seven cases were diagnosed with a mean annual incidence of 0.5 per 100,000 population (unpublished data). In southern Dalmatia, Leishmania exposure was higher than expected ( $8 \%$ seroprevalence), despite the lack or small number of clinical cases and apparently lower risk of infection than observed for central Dalmatia.

As expected, the seroprevalence was significantly lower in residents of continental areas of Croatia; in fact all but one person (a 40 year-old woman) were seronegative. As these regions are not considered to be endemic for sandflies, we cannot exclude the possibility that the one seropositive person could have been infected while traveling to the Croatian littoral where people from continental areas often spend their summer vacations.

The same possibility of travel-acquired infection with consecutive seroconversion has to be taken in account when the seemingly northward spread of asymptomatic leishmaniasis is interpreted. One could also speculate that autochthonous Leishmania infection may occur due to the observed spread of sandflies to 
TABLE 4

Seroprevalence of anti-Leishmania IgG by age, sex and region of residence, Croatia, 2007-2009 (n=2,035)

\begin{tabular}{|c|c|c|c|c|c|}
\hline Age group (years) & Sera tested & IgG positive (\%) & $p$ value & OR & $95 \% \mathrm{Cl}$ \\
\hline $0-9$ & 177 & $31(17.5)$ & $0.016^{a}$ & 2.19 & $(1.16-4.14)$ \\
\hline 10-19 & 272 & $39(14.3)$ & $0.048^{a}$ & 1.84 & $(1.01-3.38)$ \\
\hline $20-29$ & 250 & $18(7.2)$ & 0.992 & 1.00 & $(0.50-2.01)$ \\
\hline 30-39 & 246 & $17(6.9)$ & & Reference & \\
\hline 40-49 & 242 & $37(15.3)$ & $0.015^{\mathrm{a}}$ & 2.13 & $(1.16-3.93)$ \\
\hline 50-59 & 315 & $30(9.5)$ & 0.621 & 1.17 & $(0.63-2.19)$ \\
\hline $60-69$ & 205 & $19(9.3)$ & 0.631 & 1.18 & $(0.60-2.36)$ \\
\hline$>70$ & 290 & $30(10.3)$ & 0.374 & 1.33 & $(0.71-2.51)$ \\
\hline \multicolumn{6}{|l|}{ Sex } \\
\hline Men & 975 & $113(11.6)$ & 0.61 & 1.08 & $(0.81-1.44)$ \\
\hline Women & 1,060 & $118(11.1)$ & & Reference & \\
\hline \multicolumn{6}{|l|}{ Region } \\
\hline Adriatic islands & 653 & $61(9.3)$ & $0.003^{\mathrm{a}}$ & 20.37 & $(2.78-149.2)$ \\
\hline Adriatic coast & 1,186 & $169(14.2)$ & $0.001^{\mathrm{a}}$ & 28.51 & $(3.95-205.79)$ \\
\hline Continental sites & 196 & $1(0.5)$ & & Reference & \\
\hline
\end{tabular}

$\mathrm{Cl}$ : confidence interval; OR: odds ratio.

a Significant at level p<0.05.

some regions at the North of Croatia [1,2], especially in light of the recent finding of Phlebotomus spp. in southern Hungary near the Croatian border [16].

In agreement with other reports [21-24] our study shows that there is no difference in the prevalence of asymptomatic Leishmania infection between men and women.

In respect to age, our prevalence results differ from findings in other studies. In the present study a bimodal distribution of Leishmania seropositivity by age, with peaks in young (0-19 years) and middle-aged (40-49 years) population, was suggested for asymptomatic population. Several studies reported the age distribution of seroprevalence to Leishmania in a healthy human population so far. The authors mainly noted a higher prevalence in older people suggesting that susceptibility to $L$. infantum infection increases with age [21-23] or they claimed no association with age [24,25]. Furthermore, Davies et al. suggested seroprevalence drops rapidly with age [26]. In some of these studies $[21,23]$ age groups under 18 years were not included and/or samples were not equally distributed by age, resulting in different precision of seroprevalence estimate between different age groups. A study in Brazil, using a non-commercial ELISA found that $28.5 \%$ sera of 638 tested children aged between 0 and 5 years were positive, and concluded that infection is associated with the age of $\geq 2$ years [27]. In our study, seropositives were most likely to be aged o to 9 years. Since in Croatia VL is still predominantly paediatric disease $[6,7]$ it cannot be excluded that some of the seropositives in this age group might become symptomatic, therefore further differently designed studies with follow up of such participants are needed.

It can be concluded that compared to other parts of Croatia, seroprevalence is significantly higher in central and southern coastal as well as insular areas. This indicates the presence of asymptomatic $L$. infantum infection in humans and confirms the endemicity of these areas. This finding may be of particular importance in light of the increasing popularity of the Croatian coast and islands, from Istria to Dubrovnik, as a holiday destination for travellers from Leishmania-free areas or countries. Our data should alert physicians to consider leishmaniasis in the differential diagnosis of conditions such as unexplained febrile illness especially in immunocompromised subjects returning from these endemic areas. In addition, seropositivity observed in non-endemic areas and the higher seroprevalence in children should be investigated in the future. Therefore, further studies including clinical, parasitological, epidemiological and entomological investigation are required for elucidating the cycle of transmission, the maintenance and the role of Leishmania in human and animal health in different Croatian regions.

\section{Acknowledgements}

This work was supported by a grant from the Ministry of Science, Education and Sports of the Republic of Croatia (No. 216-0481153-1148). We thank all physicians for their valuable support in providing serum samples and in data collection for this study. 


\section{References}

1. Dujardin JC, Campino L, Ca-avate C, Dedet JP, Gradoni L, Soteriadou K, et al. Spread of vector-borne diseases and neglect of Leishmaniasis, Europe. Emerg Infect Dis. 2008;14(7):1013-8. http://dx.doi.org/10.3201/eid1407.071589. PMid:18598618. PMCid:PMC2600355.

2. Ready PD. Leishmaniasis emergence in Europe. Euro Surveill. 2010;15(10): pii=19505. Available from: http://www. eurosurveillance.org/ViewArticle. aspx?Articleid=19505. PMid:20403308.

3. Michel G, Pomares C, Ferrua B, Marty P. Importance of worldwide asymptomatic carriers of Leishmania infantum (L. chagasi) in human. Acta Trop. 2011;119(2-3):69-75. http:// dx.doi.org/10.1016/j.actatropica.2011.05.012. PMid:21679680.

4. Statistical Yearbook. Republic of Croatia, Zagreb: Central Bureau of Statistics, 2011. [Accessed 27 July, 2012]. Available from: http://www.dzs.hr/Hrv/censuses/census2011/firstres/ censusfirstres.htm

5. Bosnic S, Gradoni L, Khoury C, Maroli M. A review of Leishmaniasis in Dalmatia (Croatia) and results from recent surveys on phlebotomine sandflies in three southern counties. Acta Trop. 2006;99(1):42-9. http://dx.doi.org/10.1016/j. actatropica.2006.06.009. PMid:16876101.

6. Miščević Z, Milutinović M, Ivović V. Fauna and distribution of sandflies (Diptera, Phlebotomidae) in Yugoslavia, Croatia, Macedonia and their role in the transmission of parasitic and viral diseases. Acta Vet. (Beograd) 1998;48(2-3):163-72.

7. Tartaglia P. [Kala-Azar in Dalmatia.] Higijena. 1949;1(1-3):3209. Croatian.

8. Tartaglia P. [Visceral and cutaneous leishmaniasis in Dalmatia]. Liječ Vjesn 1957;79(6):511-22. Croatian.

9. Punda-Polić V, Sardelic S, Bradaric N. Visceral leishmaniasis in southern Croatia. Lancet 1998; 351(9097):188. http://dx.doi. org/10.1016/S0140-6736(05)78208-8

10. Mulic R, Custovic A, Ropac D, Tripkovic I, Stojanovic $D$, Klismanic Z. Occurrence of visceral and cutaneous leishmaniasis in Croatia. Mil Med. 2009;174(2):206-11. PMid:19317205

11. Zivicnjak T, Martinkovic F, Marinculic A, Mrljak V, Kučer N, Matijatko V, Mihaljevic Z and Baric-Rafaj R. A seroepidemiologic survey of canine visceral leishmaniasis among apparently healthy dog in Croatia. Vet Parasitol. 2005;131(1-2):35-43. http://dx.doi.org/10.1016/j. vetpar.2005.04.036. PMid:15946800.

12. European Commission. Commission Implementing Decision of 8 August 2012 amending Decision 2002/253/EC laying down case definitions for reporting communicable diseases to the Community network under Decision No 2119/98/EC of the European Parliament and of the Council (notified under document C(2012) 5538). Official Journal of the European Union L 262. 2012;55. [Accessed 4 July 2013]. Available from: http:// eur-lex.europa.eu/LexUriServ/LexUriServ.do?uri=0J:L:2012:26 2:FULL:EN:PDF

13. Croatian National Institute of Public Health. Definitions of diseases that are defined by the Law on the Protection of infectious diseases, including diseases that are not specified by the European Union. Croatian. [Accessed 4 July 2013]. Available from: http://www.hzjz.hr/epidemiologija/definicije zb_02.pdf

14. Croatian National Institute of Public Health. [Accessed 27 July 2012]. Available from: http://www.hzjz.hr/publikacije/ hzs_ljetopis/index.htm

15. Wenzl H, Petritsch W, Decrinis M, Schreiber F, Warnkross $\mathrm{H}$, Pristautz H, Krejs G]. [Kala-azar from Croatia]. Wien Klin Wochenschr. 1992;104(24):757-60. German. PMid:1337639.

16. Farkas R, Tánczos B, Bongiorno G, Maroli M, Dereure J, Ready PD. First surveys to investigate the presence of canine leishmaniasis and its phlebotomine vectors in Hungary. Vector Borne Zoon Dis. 2011;11(7):823-34. http://dx.doi.org/10.1089/ vbz.2010.0186. PMid:21254904.

17. Kelly H, Riddell MA, Gidding HF, Nolan T, Gilbert GL. A random cluster survey and a convenience sample give comparable estimates of immunity to vaccine preventable diseases in children of school age in Victoria, Australia. Vaccine 2002;20(25-26):3130-6. http://dx.doi.org/10.1016/ S0264-410X(02)00255-4.

18. Federico G, Damiano F, Caldarola G, Fantini C, Fiocchi V, Ortona L. A seroepidemiological survey on Leishmania infantum infection. Eur J Epidemiol. 1991:7(4):380-3. http://dx.doi. org/10.1007/BFo0145003. PMid:1915791.

19. Marty P, Lelievre A, Quaranta JF, Rahal A, Gari-Toussaint M, Le Fichoux Y. Use of the leishmanin skin test and western blot analysis for epidemiological studies in visceral leishmaniasis areas: experience in a highly endemic focus in Alpes-Maritimes
(France). Trans R Soc Trop Med Hyg. 1994;88(6):658-9. http:// dx.doi.org/10.1016/0035-9203(94)90214-3

20. Sever-Prebilić M, Prebilić I, Seili-Bekafigo I, Dokić S, Ivaniš N, Načinović-Duletić A, et al. A case of visceral leishmaniasis in the northern Adriatic region. Coll Antropol. 2002;26(2):545-50. PMid:12528279.

21. Biglino A, Bolla C, Concialdi E, Trisciuoglio A, Romano A, Ferroglio E. Asymtomatic Leishmania infantum infection in an area of northwestern Italy (Piedmont region) where such infections are traditionally nonendemic. J Clin Microbiol. 2010;48(1):131-6. http://dx.doi.org/10.1128/JCM.00416-09. PMid:19923480. PMCid:PMC2812267.

22. Garrote JI, Gutierrez PM, Lopez Izquierdo R, Duenas MA, Zarzosa P, Canavate C, et al. Seroepidemiological study of Leishmania infantum infection in Castilla-Leon, Spain. Am Trop Med Hyg. 2004;71(4):403-6. PMid:15516634.

23. Diza E, Kansouzidou A, Gerou S, Vezyri E, Metllidis S, Antoniadis A. Leishmaniasis in Northern Greece: seroprevalence of the infection and incidence of the disease during the period 2001-2006. Eur J Clin Microbiol Infect Dis. 2008;27(10):997-1003. http://dx.doi.org/10.1007/s10096-0080538-y. PMid:18512088.

24. Papadopulou C, Kostoula A, Dimitriou D, Panagiou A, Bobojianni C, Antoniades G. Human and canine leishmaniasis in asymptomatic and symptomatic population in Northwestern Greece. J Infect. 2005;50(1):53-60. http://dx.doi.org/10.1016/j. jinf.2004.05.004. PMid:15603841.

25. Lima ID, Queiroz JW, Lacerda HG, Queiroz PV, Pontes NN, Barbosa JD, et al. Leishmania infantum chagasi in northeastern Brazil: asymptomatic infection at the urban perimeter. Am J Trop Med Hyg. 2012;86(1):99-107. http://dx.doi.org/10.4269/ ajtmh.2012.10-0492. PMid:22232458. PMCid:PMC3247116.

26. Davies CR, Mazloumi Gavgani AS. Age, acquired immunity and the risk of visceral leishmaniasis: a prospective study in Iran. Parasitology. 1999:119(3):247-57. http://dx.doi.org/10.1017/ So031182099004680.

27. Caldas AJ, Costa JM, Silva AA, Vinhas V, Barral A. Risk factors associated with asymptomatic infection by Leishmania chagasi in north-east Brazil. Trans R Soc Trop Med Hyg. 2002;96(1):218. http://dx.doi.org/10.1016/S0035-9203(02)90227-0 